\title{
A MEDICINA EM GOIÁS E A FACULDADE DE MEDICINA DE RIBEIRÃO PRETO
}

THE MEDICINE IN THE STATE OF GOIAS AND

THE FACULTY OF MEDICINE OF RIBEIRÃO PRETO

Joffre Marcondes de Rezende, Anis Rassi

Professores Eméritos da Faculdade de Medicina da Universidade Federal de Goiás CoRRESPONDÊNCIA:Joffre M. de Rezende - (jmrezende@cultura.com.br). Av. B, 435, Setor Oeste / 74110-130 - Goiânia, GO

Nossos primeiros contatos com a Faculdade de Medicina de Ribeirão Preto antecederam a fundação da Faculdade Medicina de Goiás.

Interessados no estudo da Doença de Chagas e da sua relação com o megaesôfago e o megacolo endêmicos, iniciamos a partir de 1955 uma investigação dos casos que atendíamos nos consultórios e nos hospitais de Goiânia.

Os recursos diagnósticos disponíveis na época em Goiânia eram muito limitados. Contávamos apenas com a colaboração prestimosa de nosso colega Carlos Borges, em seu laboratório particular de análises clínicas e com os dados epidemiológicos fornecidos pelo Departamento Nacional de Endemias Rurais em Goiás, na ocasião sob a direção do Dr. Atila Gomes de Carvalho.

Buscamos, então, o auxílio da Faculdade de Medicina de Ribeirão Preto nos Departamentos de Parasitologia, Patologia, Medicina Preventiva e, posteriormente no Departamento de Clínica Médica, nas pessoas dos Professores Mauro Pereira Barreto, Astolpho Ferraz de Siqueira, José Lima Pedreira de Freitas, Hélio Lourenço de Oliveira, Renato Alves de Godoy, Clovis Buhler Vieira, Dalmo de Souza Amorim e Francisco Ferriolli Filho.

Encontramos a maior boa vontade e o apoio de todos os que procuramos, que se dispuseram a colaborar com o nosso trabalho. O Departamento de Parasitologia se dispôs a realizar as reações sorológicas para Doença de Chagas de nossos pacientes por técnica quantitativa, assim como fornecer triatomíneos para os xenodiagnósticos necessários ao controle parasitológico dos primeiros ensaios de tratamento específico. Durante 33 anos foram examinados naquele Departamento 15.078 soros que eram remetidos por um de nós (AR) de Goiânia a Ribeirão Preto, inicialmente apenas para a reação de fixação de complemento e, a partir de 1973, também para a reação de imunofluorescência. Cerca de 100.000 foi o número de triatomíneos que recebemos naquele período.

No Departamento de Patologia, o Prof. Fritz Köberle colocou o seu Serviço à nossa disposição e manifestou seu desejo de manter um intercâmbio permanente com o meio médico goiano, já que havia um interesse comum, que era o estudo da Doença de Chagas.

Em 1956 realizava-se em Uberaba, MG, o VIII Congresso Médico do Triângulo Mineiro e Brasil Central, no qual um dos temas oficiais sugerido pela Associação Médica de Goiás foi "Doença de Chagas no Estado de Goiás". Foram relatores do tema:

Atila G. de Carvalho e Ottoni T. Verano Epidemiologia

Carlos Borges - Diagnóstico Laboratorial

Anis Rassi e Omar Carneiro - Cardiopatia

Joffre M. de Rezende - Megaesôfago.

Dirigiu a sessão o Prof. José Lima Pedreira de Freitas, especialmente convidado pela Comissão Organizadora do Congresso. Do seu comentário final, destacamos o seguinte trecho:

"Somente através de contatos cada vez mais íntimos com os médicos que labutam na clínica civil e particularmente com aqueles que trabalham mais longe dos centros científicos, poderemos contribuir para que uma Faculdade de Medicina como a de Ribeirão 
Preto cumpra da melhor forma sua finalidade número um, qual seja a de formar médicos úteis para o País, os quais exerçam a profissão com pleno conhecimento das novas conquistas científicas e das necessidades do País".

Em 1956, o Prof. Fritz Köberle prestigiava a Revista Goiana de Medicina, que havia sido fundada um ano antes pela Associação Médica de Goiás, publicando na mesma o seu artigo Patogênese dos megas (Rev. Goiana Med. 2: 101-110, 1956).

No ano seguinte, o Prof. Köberle publicou na Revista Goiana de Medicina o seu artigo Patogenia da Moléstia de Chagas, que se tornou clássico (Rev. Goiana Med. 3:155-180, 1957). A propósito deste artigo, o editor da revista fez o seguinte comentário:

"Dispondo de tantas revistas médicas no País, por certo superiores à nossa, honrou-nos o Prof. Köberle com esta distinção. Seus trabalhos sobre moléstia de Chagas têm sido quase todos publicados em língua alemã e em periódicos europeus. É este o $3^{\circ}$ trabalho que escreve em língua portuguesa e o $2^{\circ}$ que esta revista tem o privilegio de divulgar" (Rev. Goiana Med. 3: 216, 1957). A partir de então, o Prof. Köberle veio várias vezes a Goiânia proferir palestras, participar de Congressos e Jornadas ou acompanhando visitantes ilustres de instituições estrangeiras.

Por ocasião do 1 Congresso Internacional sobre a Doença de Chagas, que se realizou no Rio de Janeiro de 5 a 11 de julho de 1959, foi marcante a contribuição dos pesquisadores da Faculdade de Medicina de Ribeirão Preto. Numa época em que ainda se contestava a etiologia chagásica dos megas, as pesquisas do Prof. Köberle relativas ao comprometimento generalizado do sistema nervoso autônomo na Doença de Chagas não foram bem aceitas e tivemos oportunidade de contribuir com subsídios clínicos e epidemiológicos em apoio às suas idéias.

A Universidade Federal de Goiás, alguns anos mais tarde, reconhecendo a contribuição do Prof. Köberle ao desenvolvimento da Medicina em Goiás concedeu-lhe o título de Professor Honoris Causa (Rev. Goiana Med. 25:195-198, 1979).

A aproximação com outros Departamentos, especialmente o de Clínica Médica, se deu após a criação da Faculdade de Medicina de Goiás, cujo fundador e primeiro Diretor, Prof. Francisco Ludovico de Almeida Neto era um grande admirador do Prof. Zeferino Vaz, o idealizador da Faculdade de Medicina de Ribeirão Preto, a qual passou a ser o modelo em que deveríamos nos inspirar, guardadas as proporções e as características próprias de cada Instituição.

Os primeiros tempos da Faculdade de Medicina de Goiás, fundada inicialmente como entidade particular e incorporada à Universidade Federal de Goiás em dezembro de 1960, foram bastante dificeis pela carência de recursos humanos, técnicos e financeiros.

O Diretor da nossa Faculdade solicitou a colaboração da Faculdade de Medicina de Ribeirão Preto para preencher algumas lacunas no corpo docente. No ano de 1961, o curso de parasitologia em nossa Faculdade foi ministrado pelo Prof. Astolpho Ferraz de Siqueira, e em 1962, pelo Prof. Francisco Ferriolli Filho, ambos professores da Faculdade de Medicina de Ribeirão Preto.

No ano de 1963, a nossa Faculdade contou com a valiosa participação do Prof. Nagib Haddad, do Departamento de Medicina Preventiva, que ministrou o primeiro curso de Higiene e Medicina Preventiva.

Certamente estimulados pelos professores do Departamento de Medicina Preventiva, os estudantes do curso médico integrantes da Liga Brasileira de Combate à Doença de Chagas, entidade fundada em Ribeirão Preto pelo Centro Acadêmico Rocha Lima, realizaram em Goiânia, em fevereiro de 1961, uma exposição educativa sobre a Doença de Chagas, no sentido de esclarecer a população sobre a importância dessa endemia e dos meios de sua prevenção. Representando o Secretário de Saúde do Estado de Goiás, Dr. José Peixoto da Silveira, que se encontrava ausente de Goiânia na ocasião, um de nós (JMR) assim se manifestou: “...nós, médicos de Goiás, estamos ligados àquele modelar instituto de ensino e pesquisa que é a Faculdade de Medicina de Ribeirão Preto, a qual vem colaborando com a medicina goiana na busca de soluções e no equacionamento de importantes problemas de saúde pública e patologia regional, dentre os quais avulta a Doença de Chagas". .."Louvamos o patriótico trabalho do Centro Acadèmico Rocha Lima e agradecemos a inestimável colaboração dos acadêmicos de Ribeirão Preto".

Do Departamento de Cirurgia, dirigido pelo Prof. Ruy Ferreira Santos, tivemos a colaboração de seu assistente, Prof. Luiz Heraldo Câmara Lopes dos Anjos, que veio a Goiânia fazer demonstração da operação por este idealizada, de esofagectomia subtotal no tratamento cirúrgico do megaesôfago avançado.

Na qualidade de professores de Clínica Médica e em companhia do primeiro Diretor do Hospital 
das Clínicas de nossa Faculdade, Prof. Geraldo Pedra, em mais de uma oportunidade buscamos na Faculdade de Medicina de Ribeirão Preto orientação para a estruturação administrativa, técnica e didática dos serviços médicos do Hospital de Goiânia. Em uma das vezes, um de nós (JMR) trouxe a Goiânia em uma penosa viagem de carro, em dia chuvoso, o Prof. Hélio Lourenço de Oliveira, para que ele observasse de visu a organização e o funcionamento do Departamento de Clínica Médica e do próprio Hospital, e nos oferecesse sugestões para o seu aprimoramento.

Estabeleceu-se desde então, um contato permanente com o Departamento dirigido pelo Prof. Hélio Lourenço de Oliveira que muito nos beneficiou, especialmente na área de Gastroenterologia.

Quando o Departamento de Clínica Médica de nossa Faculdade conseguiu, a duras penas, adquirir um polígrafo para manometria do esôfago, tivemos de recorrer ao Prof. Renato Alves de Godoy, quem, com a maior boa vontade, se deslocou até Goiânia e aqui permaneceu o tempo necessário para colocar o aparelho em funcionamento e ensinar a um de nós (JMR) o seu manuseio. O Prof. Godoy, sempre prestativo, tornou-se um colaborador permanente na orientação dos trabalhos de pesquisa sobre a forma digestiva da Doença de Chagas que se realizaram em nossa Faculdade e por mais de uma vez retornou a Goiânia para transmitir suas idéias criativas e sua experiência. Esse espirito de parceria estendeu-se a seus colegas mais jovens da equipe: Ulysses G. Meneghelli, Ricardo Brandt de Oliveira, Walfredo Padovan, Roberto Oliveira Dantas e Luiz Emesto de Almeida Troncon.

Nossa Faculdade contou com a presença de vários docentes da Faculdade de Medicina de Ribeirão Preto na constituição de bancas examinadoras de teses de doutoramento antes da reforma do ensino superior e de dissertação de Mestrado após a refor- ma. Um de nós (JMR) teve, igualmente, o privilégio de participar de bancas examinadoras em concursos e defesas de teses na Faculdade de Medicina de Ribeirão Preto, o que nos deu a oportunidade de acompanhar as pesquisas que se realizavam naquela instituição, em particular sobre a Doença de Chagas.

Diversos trabalhos de pesquisa sobre diferentes aspectos da doença de Chagas foram realizados em colaboração em ambas as Faculdades, dos quais participamos, e que foram publicados em revistas nacionais e internacionais.

A Revista Goiana de Medicina continuou a ser prestigiada pelos professores da Faculdade de Medicina de Ribeirão Preto, nela publicando artigos científicos originais, que muito contribuíram para a sua projeção no cenário internacional. Ao comemorar 30 anos de existência, em 1985, esta Revista contabilizava nada menos que 50 trabalhos com a participação de docentes da Faculdade de Medicina de Ribeirão Preto.

Ao ser fundada a Academia Goiana de Medicina em 1988, um de nós (AR), na qualidade de membro fundador, escolheu o nome do Prof. José Lima Pedreira de Freitas como patrono de sua cadeira, a de número 30 , numa homenagem não só ao ilustre professor como à Faculdade a que ele pertenceu.

A Doença de Chagas foi, sem dúvida, o elo principal que uniu a Faculdade de Medicina de Goiás à Faculdade de Medicina de Ribeirão Preto e manteve um proveitoso intercâmbio entre as duas instituições ao longo dos anos.

Ao ensejo das comemorações do cinqüentenário da Faculdade de Medicina de Ribeirão Preto prestamos este depoimento para registrar a participação que essa Faculdade teve no desenvolvimento da medicina em Goiás, assim como na estruturação e crescimento da Faculdade de Medicina da Universidade Federal de Goiás. 